\title{
Adaptation Potential of Farmers' Own Risk Management Strategies in Smallholder Agriculture: Some Evidence from India
}

Pratap Singh Birthal ( $\sim$ ps.birthal@icar.gov.in )

National Institute of Agricultural Economics and Policy Research https://orcid.org/0000-0002-72876269

Jaweriah Hazrana

NCAP: National Centre for Agricultural Economics and Policy Research

Digvijay Negi

Indira Gandhi Institute of Development Research

\section{Research Article}

Keywords: Risk management strategies, Agricultural productivity, Downside risk

Posted Date: April 12th, 2021

DOl: https://doi.org/10.21203/rs.3.rs-393109/v1

License: (c) (i) This work is licensed under a Creative Commons Attribution 4.0 International License. Read Full License 


\title{
Adaptation Potential of Farmers' Own Risk Management Strategies in
} Smallholder Agriculture: Some Evidence from India

\author{
Pratap S Birthal (ps.birthal@icar.gov.in; psbirthal@yahoo.com) \\ ICAR-National Institute of Agricultural Economics and Policy Research, New Delhi, 110 012, India \\ Jaweriah Hazrana (jaweriah.harzana@gmail.com) \\ ICAR-National Institute of Agricultural Economics and Policy Research, New Delhi, 110 012, India \\ Digvijay S Negi(digvijay@igidr.ac.in; digvijaynegi12@gmail.com) \\ Indira Gandhi Institute of Development Research, Mumbai 400 065, India
}

\section{Abstract}

Farmers in developing countries are more exposed to frequent climatic shocks, and they, in the absence of a well-functioning market for crop insurance, rely on their own risk management strategies to reduce adverse effects of climatic shocks on agricultural production. This study evaluates adaptation benefits of farmers' own risk management strategies in Indian agriculture, and comes out four key highlights. One, farmers, based on their historical exposures to climatic shocks, resource endowments and access to information and credit, often use more than one risk management measure at a time. Two, all risk management strategies, including the mitigation, transfer and coping, contribute towards improving agricultural productivity and reducing downside risk exposure, but it is the risk mitigation strategy that is more efficient. Three, joint adoption of risk management strategies generates even larger adaptation benefits. Four, although joint adoption of these strategies is positively associated with farm size, with information and liquidity constraints relaxed probability of their joint adoption is likely to increase on smaller farms.

\section{Keywords}

Risk management strategies, Agricultural productivity, Downside risk

\author{
JEL classification Q10, Q54, Q18
}




\section{Introduction}

31 Farmers' frequent exposure to climatic shocks is one of the main causes of low agricultural productivity, food and nutrition insecurity, and persistent poverty in developing countries (Bhandari et al. 2007, Hill and Mejia-Mantilla 2015, Duong et al. 2019, Hansen et al. 2019). For example, In India the negative rainfall shocks (or droughts) in India are found to reduce household income by $25-60 \%$ and increase head-count poverty by $12-33 \%$ (Bhandari et al. 2007). Similarly, the negative rainfall shock have been reported to reduce household consumption by $37 \%$ in Nigeria (Amare et al. 2018) and $15 \%$ in Uganda (Hill and MejiaMantilla 2015).

Further, poor people and poor economies suffer more from climatic shocks. Dell et al. (2012) show growth effect of climatic shocks highly negative for agriculture in developing countries than in developed countries. In India, climatic hazards have been found to reduce agricultural growth by about $25 \%$, and the impact being larger in low-income and more agrarian states (Birthal et al. 2021). On the other hand, these lack access to financial resources, institutions and technologies for risk management (Hansen et al. 2019, Ali et al. 2020). Formal markets for crop insurance are underdeveloped (Binswanger-Mkhize 2012, Ali et al. 2020), that compel smallholder farmers to use their own risk management strategies ( Mendelsohn 2010) such as the diversification into high-value and stress-tolerant crops, animal husbandry and non-farm activities; climate-resilient agronomic practices; out-migration, borrowings and sale of assets (Deressa et al. 2010, Kakraliya et al. 2018, Birthal and Hazrana 2019, Collins-Sowah and Henning 2019, Aryal et al. 2020). Based on an extensive review of empirical literature, Altieri and Nicholls (2013) conclude that smallholder farmers use a number of traditional 
52 strategies to deal with climate variability, and it is now increasingly recognized that a

53 combination of traditional practices and scientific innovations is a robust path to increase

54 productivity, sustainability and resilience of smallholder agriculture.

Several studies have assessed adaptation potential of traditional risk management measures, but most of these focus either one or two measures, while in practice farmers use multiple measures at a time (Jodha et al. 2012, Amondo et al. 2019). Only a few studies have investigated adaptation benefits of multiple risk management measures (Kassie et al. 2014, Teklewold et al. 2017, Vigani and Kathage 2019, Collin-Sowah and Henning 2019, Amondo et

60 al. 2019). This study assesses adaptation benefits of farmers' own risk management strategies

61 in India ${ }^{1}$ utilizing information from a large-scale nationally representative farm survey (Gol

62 2015). The survey, although, not targeted at risk management, provides useful information

63 on several farm and non-farm activities that provide farmers a cushion against climatic and non-climatic shocks. We identify such activities from this survey, and based on their risk functions classify these into risk avoidance/mitigation, risk transfer and risk coping strategies.

The study employs multinomial endogenous switching regression technique, and finds that (i) often the farmers adopt more than one risk management measure at a time, and (ii) the 68 mitigation-based measures more efficient at reducing risk and improving agricultural productivity, but their joint adoption along with risk transfer and coping measures generates even larger adaptation benefits. These findings have two important policy implications. One, these serve as a guide for farmers to take informed decisions on the choice of different risk management measures. Two, at policy level the evidence on the productivity-risk tradeoffs

\footnotetext{
${ }^{1}$ More than $86 \%$ of the landholdings in India are of size less than or equal to two hectares.
} 
between risk management strategies provides a feedback to policymakers to identify efficient and inclusive adaptation measures and mainstream these into the risk management policy.

Rest of the paper is structured as follows. Following section describes data sources, and section 3 discusses empirical approach. Section 4 provides descriptive statistics of the variables that may differentiate farmers in their choice of risk management strategies and their outcomes. The factors influencing farmers' choice of risk management strategies and their adaptation benefits are presented in section 5 , and section 6 discusses these in relation to the available empirical evidence. Concluding remarks are made in the last section.

\section{Data sources}

The study utilizes data from a large-scale nationally representative farm survey conducted in 2012-13 by the National Sample Survey Office (NSSO) of the Government of India (Gol 2015). The survey collected information from 35200 households spread throughout the country. It provides information on several aspects of farming and farm households, including the area under crops, their outputs and monetary values; landholding size, land-lease; irrigation; livestock ownership and sales; participation in labor markets and non-farm activities; and agricultural information, institutional credit and crop insurance. We exploit this survey to identify important agricultural practices that farmers follow as a part of their farm management and livelihoods, but also provide a cushion against climatic shocks.

To understand farmers' adaptive response to climate shocks, the household-level variables are integrated with climate variables (i.e., precipitation and temperature) at district-level. The climate data have been extracted from the gridded data on daily minimum and maximum temperature (at $0.5 \times 0.5$ grid) and precipitation (at $0.25 \times 0.25$ grid) sourced from the India 
Meteorological Department (IMD), Ministry of Earth Sciences, Government of India. We derive district-level estimates of climate variables assigning each weather station to a district whose centroid is nearest to it, and then calculate average of the concerned variable recorded at all the weather stations assigned to the district. Our climate dataset pertains to the period from 1980 to 2011, and from this we estimate positive and negative deviations in temperature and rainfall from their respective historical means.

101 Literature shows that farmers adopt several measures of risk management (see, Birthal and Negi 2012, Amare et al. 2018, Birthal et al. 2019, Call et al. 2019, Birthal and Hazrana 2019, Duong et al. 2019, Hansen et al. 2019), and based on their risk functions these can be categorized as (i) risk mitigating, (ii) risk transferring, and (iii) risk coping. From the farm survey data, we identify diversification into high-value crops, animal husbandry and non-farm

106 business activities as important risk mitigation measures. Crop insurance and renting-out

107 land to comprise our risk transfer strategy. Guaranteed wage employment, out-migration,

108 remittances and livestock sales are found as important risk coping measures. A few of these 109 have been in use traditionally as component of farm management, while others might have 110 been adopted instantaneously in response to a climatic shock.

\section{Empirical approach}

112 A risk-averse will adopt a risk management measure if it the expected utility from its adoption

113 is higher than without its adoption. Further, given the resource endowment, he/she will

114 choose amongst the available measures the one that provides higher expected utility. Since

115 risk management measures are adopted a priori without knowing their actual outcomes,

116 these can be expressed as an ex-ante comparison of their expected utilities (Koundouri et al.

117 2006, Mukasa 2018). Thus, the farmer chooses a measure from the available alternatives, $\mathrm{j}=$ 
$1181, \ldots, N$, that maximizes his/her expected utility, i.e., $\mathrm{E}[\mathrm{u}(\mathrm{k})]=\int \mathrm{kf}(\mathrm{k}) \mathrm{u}(\mathrm{k})$; where $\mathrm{u}(\mathrm{k})$ is a

119 real-valued function that represents the utility from measure $k$, and $f(k)$ is the probability

120 density function of $k$.

121 Following recent literature (e.g., Di Falco and Veronesi 2013, Teklewold et al. 2013, Kassie et

122 al. 2015, Teklewold et al. 2017) this study employs multinomial endogenous switching

123 regression (MESR) technique to evaluate adaptation potential of different risk management

124 strategies. MESR belongs to the category of instrumental variable (IV) approaches that correct

125 for the unobserved heterogeneity and the selection bias in the outcome generating process

126 (Bourguignon et al. 2007, Vigani and Kathage 2019).

127 MESR is a two-step econometric procedure. It first evaluates the choice of a measure $j$ from

$128 N$ mutually exclusive measures, i.e., $j=1, \ldots ., N$. Assuming that the choice of a risk

129 management measure is a function of exogenous variables, and all the observations are

130 independent, the expected utility from adoption of multiple measures can be defined by a

131 latent variable $Y_{i j}^{*}$ as:

$132 Y_{i j}^{*}=\boldsymbol{C}_{i} \boldsymbol{\alpha}_{j}+\xi_{i j}$

$133 \quad Y_{i}= \begin{cases}1 \text { iff } Y_{i 1}^{*}>\max _{k \neq 1}\left(Y_{i k}^{*}\right) & \text { or } \varepsilon_{i 1}<0 \\ \vdots \quad & \vdots \\ N \text { iff } Y_{i N}^{*}>\max _{k \neq N}\left(Y_{i k}^{*}\right) & \text { or } \varepsilon_{i N}<0\end{cases}$

134 Where, $\varepsilon_{i j}=\max _{k \neq j}\left(Y_{i k}^{*}-Y_{i j}^{*}\right)<0$, that is, the farmer $i$ selects measure $j$ if it provides more 135 utility than an alternative measure $k$; and $k \neq j$. 
136 In selection equation, $\boldsymbol{C}_{\boldsymbol{i}} \boldsymbol{\alpha}_{\boldsymbol{j}}$ is the deterministic component that influences probability of

137 choosing measure $j$ through observable household characteristics and/or risk factors. $\xi_{i j}$, is

138 an idiosyncratic stochastic component that captures effect of unobservable factors.

139 Parameters of the latent variables in Eq. (1) are estimated using maximum likelihood

140 estimator (MLE). Under the assumption that $\xi_{i j}$ is identically and independently Gumbel

141 distributed the probability that farmer $i$ with a set of characteristics $C_{i}$ adopts measure $j$ can

142 be specified as a multinomial logit function:

$143 P_{i j}=P\left(\varepsilon_{i j}<0 \mid \boldsymbol{C}_{\boldsymbol{i}}\right)=\frac{\exp \left(\boldsymbol{C}_{\boldsymbol{i}} \boldsymbol{\alpha}_{\boldsymbol{j}}\right)}{\sum_{k=1}^{N} \exp \left(\boldsymbol{C}_{\boldsymbol{i}} \boldsymbol{\alpha}_{\boldsymbol{j}}\right)}$

144 Equation (3) assumes independence of irrelevant alternatives (IIA), i.e., probability of 145 choosing a measure is independent of other measures. Bourguignon et al. (2007) show that a

146 multinomial logit function provides robust selection bias correction for outcome equation

147 even if the assumption of IIA is violated.

148 In its second step, MESR generates bias-corrected outcomes. With multiple adaptation

149 measures, the vector of outcome variables is assumed to be a linear function of the 150 explanatory variables. Hence, the stochastic function to evaluate outcome of each measure 151 can be expressed as:

$152\left\{\begin{array}{cc}\text { Regime 1: } & I_{i 1}=\boldsymbol{X}_{\boldsymbol{i}} \boldsymbol{\beta}_{\boldsymbol{i}}+u_{i 1} \text { if } Y_{i}=1 \\ \vdots & \vdots \\ \text { Regime N }: & I_{i N}=\boldsymbol{X}_{\boldsymbol{i}} \boldsymbol{\beta}_{\boldsymbol{N}}+u_{i N} \text { if } Y_{i}=\mathbf{N}\end{array}\right.$ 
153 Where, $I_{i}$ is the outcome variable for regime 1 to $\mathrm{N}, \boldsymbol{X}_{\boldsymbol{i}}$ is a vector of exogenous variables

154 that impact the outcome, and $u_{i}$ is the random error term.

155 If error terms in selection and outcome equations are correlated, then OLS estimates of Eq.

156 (4) are inconsistent. The MESR takes into consideration correlation between error terms

157 (Bourguignon et al. 2007). The correction for endogenous selection of risk management 158 measures can be expressed as:

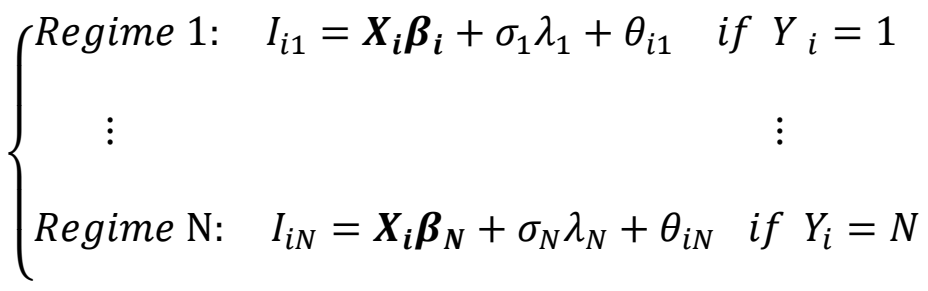

160 Where, $\sigma_{j}$ is the covariance between $\varepsilon_{i}$ and $u_{i}, \theta_{i}$ is an error term with an expected value of

161 zero, and $\lambda_{j}$ is the inverse Mills ratio (IMR) estimated from the probabilities generated from

162 Eq. (3).

163 A single selectivity correction term is generated for each risk management measure, and it is

164 included in the relevant outcome equation. To account for the possible heteroscedasticity 165 due to $\lambda_{j}$ the standard errors in Eq. (5) are bootstrapped.

166 The proper identification of MESR requires that order condition to be satisfied, i.e., vector $\boldsymbol{C}_{\boldsymbol{i}}$

167 should contain at least one variable that is not included in vector $\boldsymbol{X}_{\boldsymbol{i}}$. The additional variables serve as instruments, i.e., these are correlated with farmer's adoption of a risk management

169 measure, and not with its outcome. 
170 The estimates of MESR are utilized to calculate average treatment effects (ATT) on the

171 treated. For the purpose, we construct the following counterfactuals for the treated, i.e.,

172 those who had adopted a risk management measure:

173 Adopters with adoption (actual adoption in the sample):

$174 E\left(I_{i N \neq 1} \mid Y_{i}=N_{\neq 1}\right)=\boldsymbol{X}_{\boldsymbol{i}} \boldsymbol{\beta}_{N \neq 1}+\sigma_{N \neq 1} \lambda_{i N \neq 1}$

175 Non-adopters without adoption (actual non-adoption in the sample):

$176 E\left(I_{1 i} \mid Y_{i}=1\right)=\boldsymbol{X}_{\boldsymbol{i}} \boldsymbol{\beta}_{1}+\sigma_{1} \lambda_{i 1}$

177 Adopters deciding not to adopt (counterfactual):

$178 E\left(I_{1 i} \mid Y_{i}=N_{\neq 1}\right)=\boldsymbol{X}_{i} \boldsymbol{\beta}_{1}+\sigma_{1} \lambda_{i N \neq 1}$

179 Non-adopters deciding to adopt (counterfactual):

$180 E\left(I_{i N \neq 1} \mid Y_{i}=1\right)=\boldsymbol{X}_{i} \boldsymbol{\beta}_{N \neq 1}+\sigma_{N \neq 1} \lambda_{i 1}$

181 Équations (6a) and (6b) respectively provide expected utility for adopters and non-adopters

182 of a risk management measure, and Eq. (6c) and (6d) the corresponding expected utility for

183 counterfactual cases. The expected outcomes are then used to obtain unbiased treatment

184 effects on the treated, i.e., the difference between Eq.(6a) and Eq.(6c).

185

$A T T=E\left(I_{i N \neq 1} \mid Y_{i}=N_{\neq 1}\right)-E\left(I_{1 i} \mid Y_{i}=N_{\neq 1}\right)=\boldsymbol{X}_{\boldsymbol{i}}\left(\boldsymbol{\beta}_{N \neq 1}-\boldsymbol{\beta}_{1}\right)+\lambda_{1 i}\left(\sigma_{N \neq 1}-\sigma_{1}\right)$.

186 Our outcome variables are the agricultural productivity (measured as the value of output per

187 hectare of cropped area), and its higher-order moments, i.e., variance and skewness

188 (Antle1983, Di Falco and Chavas 2009). 
190 Table 1 shows frequency distribution of risk management measures. Risk mitigating measures

191 are the most exploited - over $62 \%$ of the farm households practiced animal husbandry, $31 \%$

192 cultivated horticultural crops (i.e., vegetables, fruits, spices, medicinal and aromatic plants),

193 and $5 \%$ had owned non-farm business activities. Adoption of risk transfer measures is 194 extremely limited $-6.3 \%$ had purchased a crop insurance contract, and $4.1 \%$ had rented-out 195 land.

196 Farmers also adopt the measures that help them absorb or recover from the risk impacts.

197 Out-migration (defined as staying-away of a household-member from his/her permanent 198 residence at least for 15 day-employment), was reported by $6.7 \%$, and receipt of remittances 199 by $10.6 \%$ of the households. Livestock sales were limited to only $2.3 \%$ of the households.

200 Wage employment is one of the means of consumption smoothening during an agricultural crisis. The Government of India implements a country-wide employment scheme known as Mahatma Gandhi National Rural Employment Guarantee Act (MGNREGA) that provides guaranteed employment of 100 days to a willing household. About $13 \%$ of the households had availed benefits of this scheme. This scheme is not designed for risk management, yet it helps its participants to cope with climatic shocks (Fischer 2020). Other risk coping measures too do not directly influence farm performance, but these ease liquidity constraints on the adoption of direct risk management measures (Hansen et al. 2019).

Most farm households had adopted more than one measure at a time. Based on similarity of

209 their risk functions these are grouped as: (i) risk mitigating, (ii) risk transferring, and (iii) risk 210 coping. These strategies are combined to know the extent of their joint adoption (Table 2).

211 Overall, $85 \%$ households had adopted one or other measure. Risk mitigation was a common 
212 strategy - it was adopted by more than three-fourths of the households, either alone or in

213 conjunction with other strategies. Risk coping strategy was adopted by $31 \%$ households and

214 mostly in conjunction with risk mitigation measures. Risk transfer strategy was limited to one-

215 tenth of the households.

216 To have an idea about the adaptation potential of different risk management strategies, first

217 we look at unconditional kernel density of agricultural productivity under different adaptation

218 regimes (Figure 1). Distribution of agricultural productivity under risk mitigation and transfer

219 strategies and also their joint adoption is skewed towards right, which indicates that these

220 have potential to reduce downside risk exposure.

221 Table A1 (in the appendix) compares means of key characteristics of adopters and non222 adopters of risk management strategies. There are three sets of variables. The first set

223 includes the risk characteristics as represented by standardized deviations of rainfall and 224 temperature from their respective long-term means. The second set includes the 225 demographic (i.e., household size, age, gender and education) and institutional (i.e., access 226 to credit, information and social safety nets, and awareness of the government-determined 227 minimum support prices) characteristics that are anticipated to influence farmers' attitude 228 towards risk, and thus their choice of a risk management strategy (Cole et al. 2013). Social 229 networks may also differentiate them in their adoption decisions (Negi et al. 2020). Caste is 230 an important form of social network in India. Broadly, there are four broad caste groups, viz., 231 scheduled castes (SC), scheduled tribes (ST), other backward castes (OBCs) and upper or other 232 castes, with SC/ST at the bottom of hierarchy and upper caste at the top. The third set includes 233 the farm and location characteristics, viz., farm size, irrigation status, crop portfolio (number 234 of crops grown), and slope and altitude of the districts. Farm size and irrigation shape farmers' 
attitude towards risk, directly or mediated through crop yields. Sherrick et al. (2004) find that

236 the larger the farms, the lesser is the requirement for risk management. Irrigation, besides its

237 yield-enhancing role, also reduces the requirement for risk management (Birthal et al. 2015).

238 Further, we also control for the unobserved heterogeneity across farms by including the

239 means of important inputs, viz, fertilizers, seeds, pesticides and labor in our econometric 240 model.

241 A comparison of the characteristics of non-adopters and adopters of risk management shows

242 that a larger proportion of the adopter-households is headed by the females and the older 243 persons, rank higher in social status and have larger families. Their landholding size is larger 244 and crop portfolio is more diversified. Other factors that differentiate adopters from non245 adopters is their better access to information and institutional credit, and awareness about 246 minimum support prices (MSP).

247 MESR requires correction of selection bias through an instrumental variable (IV) which is 248 correlated with adoption of a strategy but not with its outcome. Following the extant 249 literature (e.g., Di Falco et al. 2011, Di Falco and Veronesi 2014, Kassie et al. 2015) we include 250 farmers' training in agriculture and their net asset position as the instruments. All variables 251 (except dummies and proportions) are transformed into their log equivalents.

252 The selection of instrumental variables is validated by estimating OLS and multinomial logit equations, and the test-statistics (Table 3) confirms appropriateness of our selected instruments. Further, we also conduct an exogeneity test and estimate two-stage least square (2SLS) and generalized method of moments (GMM) (Table 4 ). The Durbin and Wu-Hausman 
tests for the 2SLS, and C-statistic for the GMM could not reject the null hypothesis that

257 selected instruments are exogenous. The full set of the results are given in Tables S1 and S2.

2585 Results

\subsection{Determinants of adoption of risk management strategies}

260 'No risk management' is the base category in our selection equations; hence, the regression

261 coefficients need to be interpreted in relation to it. Table 5 presents estimates of the selection equations. The diagnostics show a good fit of the model. The Wald statistic is highly significant, rejecting the null hypothesis that regression coefficients are jointly equal to zero.

264 The chi-squared test for the joint significance of instruments is also significant.

In most selection equations, regression coefficient on the negative as well as positive rainfall deviations is significant but opposite in direction - positive on deficit rainfall, and negative on excess rainfall. The probability of joint adoption of risk management strategies is higher in case of both the positive and negative deviations in temperature. These results suggest that farmers' adaption decisions are driven by their historical exposures to climatic shocks.

Farm size has a positive and significant effect on the adoption of most risk management strategies. This means that the larger the farm size, the higher is the farmers' risk taking capacity. It should be noted that farm activities such as horticulture and animal husbandry are labor-intensive, while large farmers are less-endowed with labor, discouraging them to adopt labor-intensive activities. Our finding is contrary to that of Sherrick et al.(2004) who find that larger farms have less requirements for risk management. 
278 of risk management strategies. For example, adoption of a more diverse crop portfolio

279 discourages use of risk coping and risk transfer strategies, but motivates adoption of risk

280 mitigating strategy.

281 The influence of the household-level factors is as expected. The probability of adoption

282 increases with age and education of household-heads. Further, female-headed households

283 are more conscious towards risk management probably because of their greater concern for

284 household food security. Household size (i.e., availability of labor) too has a positive and

285 significant influence on the adoption of risk management strategies. Further, the probability

286 of adoption of most risk management strategies is higher among the lower-caste households.

287 The coefficient on information and institutional credit is consistently positive and significant

288 across all risk management strategies and their portfolios. This implies that with information

289 and liquidity constraints relaxed, the probability of adoption of risk management strategies

290 would increase. So, does the farmers' awareness about MSP. It should be noted that the

291 Government of India procures farm commodities, mainly paddy and wheat, at their minimum

292 support prices. This insulates farmers from price fluctuations and also acts as an incentive to

293 adopt new technologies and agronomic practices. On the other hand, the household's access

294 to food security nets ${ }^{2}$ seems to reduce the requirements for risk management.

\footnotetext{
${ }^{2}$ The Government of India implements the National Food Security Act, 2013 that provides an affordable access to food to about two-thirds of the country's population. Presently, an eligible household can purchase his/her entitlement of food from the public distribution system at heavily subsidized prices, i.e., rice at Rupees $3 / \mathrm{kg}$ and wheat at $2 / \mathrm{kg}$.
} 


\section{$297 \quad 5.2$ Adaptation benefits of risk management strategies}

298 Regression estimates of the outcome equations are presented through Tables A2-A4 (in the

299 appendix). The bias correction term is statistically significant in most outcome equations, 300 indicating that bias correction was important in our analysis.

301 A few factors that influence farm performance merit attention. In all outcome equations, 302 agricultural productivity is positively influenced by irrigation, information and institutional 303 credit; and negatively by farm size and food security nets. Irrigation, crop counts, and 304 information are found to reduce variance in it, while farm size, institutional credit and food 305 security nets increase it. A positive sign on a variable in skewness function means a reduction 306 in downside risk exposure. We find farm size, irrigation, credit and food security nets to 307 reduce downside risk exposure.

308 Table 5 presents adaptation benefits of different risk management strategies. All risk management strategies lead to an improvement in agricultural productivity. Risk mitigation

310 strategy, however, causes a larger improvement (25\%) compared to risk transfer (14\%) and

311 the risk coping (10\%). Nonetheless, their joint adoption, in general, has a larger potential to 312 enhance agricultural productivity.

313 All the risk management strategies, individually or jointly, also contribute towards reducing 314 variance in agricultural productivity, and the reduction is larger in case of their joint adoption.

315 Further, joint adoption of all the strategies (e.g., MTC) causes the highest reduction in 
downside risk exposure (16\%). These findings clearly demonstrate that joint adoption of risk

317 management strategies is more efficient at improving agricultural productivity and reducing

318 downside risk exposure.

\section{Discussion}

321 Do our estimates match with those reported in the literature? In Ethiopian context, Di Falco 322 and Veronesi (2014) treating use of multiple risk management measures as a single binary

323 indicator in their econometric analysis demonstrate that these reduce downside risk

324 exposure. Similarly, Shahzad and Abdulai (2019) find that in Pakistan the adaptation to

325 climate change reduces downside exposure to risk, but does not influence much the returns

326 from farming.

327 Yesuf et al. (2009) considering chemical fertilizers and soil-water conservation technology as

328 important adaptations to climate change in Ethiopian agriculture find fertilizers to reduce

329 variance but increasing downside risk exposure; and soil-water conservation reducing

330 downside risk exposure but no significant impact on variance. The adoption of drought-

331 tolerant maize is found efficient at improving yield and reducing downside risk in Nigeria and

332 Zambia (Wossen et al. 2017, Amondo et al. 2019).

333 A few studies have also investigated the impact of joint adoption of different risk 334 management measures or strategies. Kassie et al. (2015) demonstrate higher yield and risk

335 benefits from the joint adoption of crop diversification and minimum tillage practices in 336 Malawi. Similar evidence is reported by Issahaku (2020) from the joint adoption of crop 337 diversification and soil-water conservation technology in Ghana. In Ehiopia, Teklewold et al. 
338 (2017) find joint adoption of water management, improved varieties and fertilizers being

339 more efficient at improving yield and reducing downside risk exposure in maize.

340 On the other hand, some studies provide a mixed evidence on the impact of joint adoption of

341 risk management measures. Vigani and Kathage (2019) in their assessment of the impact of

342 crop insurance, production contract, production diversification and crop variety, and their

343 portfolios on total factor productivity of wheat in France and Hungary report their positive as

344 well negative impacts on downside risk exposure. They find larger negative impacts in the

345 case of more complex risk management portfolios. Collins-Sowah and Henning (2019) too

346 report similar evidence from Senegal.

347 The ambiguity in the impacts of different risk management strategies is probably due to the

348 context specificities in the probability of occurrence of climatic shocks and farmers' risk

349 preferences. Evidently, most of the above mentioned studies are location-specific based on

350 small samples. Our results are based a large dataset that allows us to control for spatial

351 contexts. Further, it covers fairly a large number of measures of risk management that are

352 typical of smallholder agriculture where farmers due to lack of a market for crop insurance

353 often use their own risk management measures, knowingly or unknowingly, as a part of their

354 farm Our findings support the claim that in smallholder agriculture a combination of 355 traditional practices and scientifically sound innovations is a robust path to increase 356 productivity, sustainability and resilience of agriculture (Altieri and Nicholls 2017).

\section{Conclusions and implications}

358 This study has evaluated the adaptation potential of farmers' own risk management 359 strategies. It highlights four key findings. One, farm households, based on their historical 360 exposure to climatic shocks use several risk management measures and often more than one 
361 at a time. Two, although farmers benefit from all risk management strategies, the risk

362 mitigation strategy generates relatively larger adaptation benefits. Three, joint adoption of

363 different risk management strategies provides even higher adaptation benefits than do the

364 individual strategies. Four, joint adoption of risk management strategies is positively

365 associated with farm size. However, with information and liquidity constraints relaxed the

366 smallholder farmers will go for adoption of multiple risk management strategies.

367 These results offer an important insight into the ways the farm households manage

368 production risks and have some important policy implications. These findings can serve as a

369 guide for farmers to take informed decisions on the use of different risk management

370 measures subject to their risk preferences and resource constraints. At policy level, the

371 evidence on productivity-risk tradeoffs between different risk management strategies

372 provides an important feedback to policymakers to identify economically more efficient and

373 inclusive risk management measures and mainstream these into agricultural research and

374 development policies, especially when the uptake of crop insurance is poor.

376 Declarations

377 Funding: The funding from this study came from the Indian Council of Agricultural Research

378 under the National Professorial Chair to the corresponding author

379 Conflicts of interest: Authors have no conflict of interest 
380 Availability of data and material: The data are available in the public domain and can be

381 obtained at cost from the concerned agencies as indicated in the section on Data sources in

382 this manuscript.

383 Code availability: Authors shall be happy to share the software codes.

\section{Authors' contributions:}

385 Dr Pratap Singh Birthal conceptualized and the idea and developed it for its implementation 386 by the team, and wrote the manuscript.

387 Dr Jaweriah Hazrana compiled the data and undertook the required econometric analysis.

388 Dr Digvijay Singh Negi helped refine the econometric results and write-up of the manuscript.

389 Ethics approval: Not applicable

390 Consent to participate: Yes

391 Consent for publication: Yes

\section{References}

393 Ali W, Abdulai A, Mishra AK (2020) Recent advances in the analyses of demand for agricultural

394 insurance in developing and emerging countries. Annual Review of Resource Economics 12(1): 411395430.

397 Altieri MA, Nicholls $\mathrm{Cl}(2017)$ The adaptation and mitigation potential of traditional agriculture in a changing climate. Climatic Change 140(1): 35-45.

399

400 Amare M, Jensen ND, Shiferaw B, Cisse JD(2018) Rainfall shocks and agricultural productivity:

401 implication for rural household consumption. Agricultural Systems 166: 79-89.

402 
403 Amondo E, Simtowe F, Rahut DB, Erenstein O(2019) Productivity and production risk effects of

404 adopting drought-tolerant maize varieties in Zambia. International Journal of Climate Change 405 Strategies and Management 11(4):570-591.

406 Antle JM (1983) Testing the stochastic structure of production: a flexible moment-based approach. 407 Journal of Business and Economic Statistics 1(3):192-201.

408 Aryal JP, Jat ML, Sapkota TB, Rahut D B, Rai M, Jat HS, Sharma PC, Stirling C (2020) Learning adaptation

409 to climate change from past climate extremes: evidence from recent climate extremes in Haryana,

410 India. International Journal of Climate Change Strategies and Management 12(1):128-146.

411 Bhandari H, Pandey S, Sharan R, Naik D, Hiwray I, Taunk SK, Sastri ASRAS (2007) Economic costs of 412 drought and rice farmers' drought-coping mechanisms in eastern India. In: Pandey S, Bhandari H, 413 Hardy B (eds) Economic costs of drought and rice farmers' coping mechanisms: A cross-country 414 comparative analysis. International Rice Research Institute, Manilla.

415 Binswanger-Mkhize HP(2012) Is there too much hype about index-based agricultural insurance? 416 Journal of Development Studies 48(2):187-200.

417 Birthal PS, Hazrana J(2019) Crop diversification and resilience of agriculture to climatic shocks: 418 evidence from India. Agricultural Systems 173: 345-354.

419 Birthal PS, Hazrana J, Negi DS (2021) Impacts of climatic hazards on agricultural growth in India.

420 Climate and Development: DOI: $\underline{\text { https://doi.org/10.1080/17565529.2020.1867045. }}$

421 Birthal PS, Negi DS, Khan MT, Agarwal S(2015) Is Indian agriculture becoming resilient to droughts?:

422 evidence from rice production systems. Food Policy 56: 1-12.

423 Bourguignon F, Fournier M, Gurgand M(2007) Selection bias corrections based on the multinomial 424 logit model: Monte-Carlo comparisons. Journal of Economic Surveys 21:174-205. 
425 Call M, Gray C, Jagger P(2019) Smallholder responses to climate anomalies in rural Uganda. World

426 Development 115:132-144.

427 Cole S, Gine X, Tobacman J, Topalova P, Townsend R, Vickery J (2013) Barriers to household risk

428 management: Evidence from India. American Economic Journal: Applied Economics 5:104-135.

429 Collins-Sowah Peron A, Henning Christian HCA(2019) Risk Management and its Implications on

430 Household Incomes. Working Papers of Agricultural Policy, No. WP2019-05, Kiel University,

431 Department of Agricultural Economics, Chair of Agricultural Policy, Kiel. Available at:

432 http://hdl.handle.net/10419/213603.

433 Deressa TT, Ringler C, Hassan RM(2010) Factors Affecting the Choices of Coping Strategies for Climate

434 Extremes: The Case of Farmers in the Nile Basin of Ethiopia. Discussion Paper No. 01032, International 435 Food Policy Research Institute, Washington DC.

436 Di Falco S, Chavas JP (2009) On crop biodiversity, risk exposure, and food security in the highlands of 437 Ethiopia. American Journal of Agricultural Economics 91(3): 599-611.

438 Di Falco S, Veronesi M (2013) How can African agriculture adapt to climate change? A counterfactual 439 analysis from Ethiopia. Land Economics 89(4): 761-784.

440 Di Falco S, Veronesi M(2014) Managing environmental risk in presence of climate change: the role of 441 adaptation in the Nile Basin of Ethiopia. Environmental and Resource Economics 57 (4): 553-77.

442 Duong TT, Brewer T, Luck J, Zander K(2019) A global review of farmers' perceptions of agricultural risks

443 and risk management strategies. Agriculture 9(10):1-16.

444 Fischer HW(2020) Policy innovations for pro-poor climate support: social protection, small-scale

445 infrastructure, and active citizenship under India's MGNREGA. Climate and Development 12(8). 
446 Gol - Government of India (2015) Situation Assessment Survey of Agricultural Households, 70th

447 Round. National Sample Survey Office, Government of India, New Delhi.

448 Hallegatte S, Bangalore M, Bonzanigo L, Fay M, Kane T, Narloch U, Rozenberg J, Treguer D, Vogt-Schilb

449 A (2016) Shock Waves: Managing the Impacts of Climate Change on Poverty. Climate Change and 450 Development Series, World Bank, Washington DC.

Hansen J, Hellin J, Rosenstock T, Fisher E, Cairns J, Stirling C, Lamanna C, van Etten J, Rose A, Campbell

B (2019) Climate risk management and rural poverty reduction. Agricultural Systems 172: 28-46.

Hill R, Mejia-Mantilla C ( 2015) Welfare and Shocks in Uganda. Background Paper prepared for the Uganda Poverty Assessment. World Bank, Washington DC.

Issahaku G(2020) Contribution of Climate-smart Agriculture to Farm Performance, Food and Nutrition Security and Poverty Reduction in Ghana. Doctoral dissertation, Faculty of Agricultural and Nutrition Sciences, Christian Albrechts Universitat zu Kiel. Jodha NS, Singh NP, Bantilan MCS(2012) Enhancing Farmers' Adaptation to Climate Change in Arid and Semi-Arid Agriculture of India: Evidences from Indigenous Practices. Working Paper Series No. 32. International Crops Research Institute for the Semi-Arid Tropics, Patancheru 502324, Andhra Pradesh, 461 India. ura SL, Jat ML (2018) Performance of portfolios of climate smart agriculture practices in a rice-wheat system of western Indo-Gangetic plains. Agricultural Water Management 202: 122-133. 
469 Theory and application to irrigation technology. American Journal of Agricultural Economics 88(3):

470 657-670.

Mukasa A N (2018) Technology adoption and risk exposure among smallholder farmers: Panel data evidence from Tanzania and Uganda. World Development 105: 299-309.

Negi DS, Birthal PS, Kumar A, Tripathi G( 2020) Farmers' social networks and the diffusion of modern crop varieties in India. International Journal of Emerging Markets https://doi.org/10.1108/IJOEM-04-

475 2020-0407.

Sherrick B J, Barry PJ, Ellinger PN, Schnitkey G D( 2004) Factors influencing farmers' crop insurance decisions. American Journal of Agricultural Economics 86(1):103-114.

478 Teklewold H, Mekonnen A, Kohlin G, Di Falco S(2017) Does adoption of multiple climate smart 479 practices improve farmers' climate resilience? Empirical evidence from the Nile Basin of Ethiopia. 480 Climate Change Economics 8(1):1-30.

481 Teklewold H, Kassie M, Shiferaw B, Kohlin G(2013) Cropping system diversification, conservation 482 tillage and modern seed adoption in Ethiopia: impacts on household income. Ecological Economics 93: 483 85-93.

484 Vigani M, Kathage $\mathrm{J}(2019)$ To risk or not to risk? Risk management and farm productivity. American 485 Journal of Agricultural Economics 101(5): 1432-1454.

486 Wossen T, Abdoulaye T, Alene A, Feleke S, Menkir A, Manyong V(2017) Measuring the impacts of 487 adaptation strategies to drought stress: the case of drought tolerant maize varieties. Journal of 488 Environmental Management 203:106-113. 
Figures

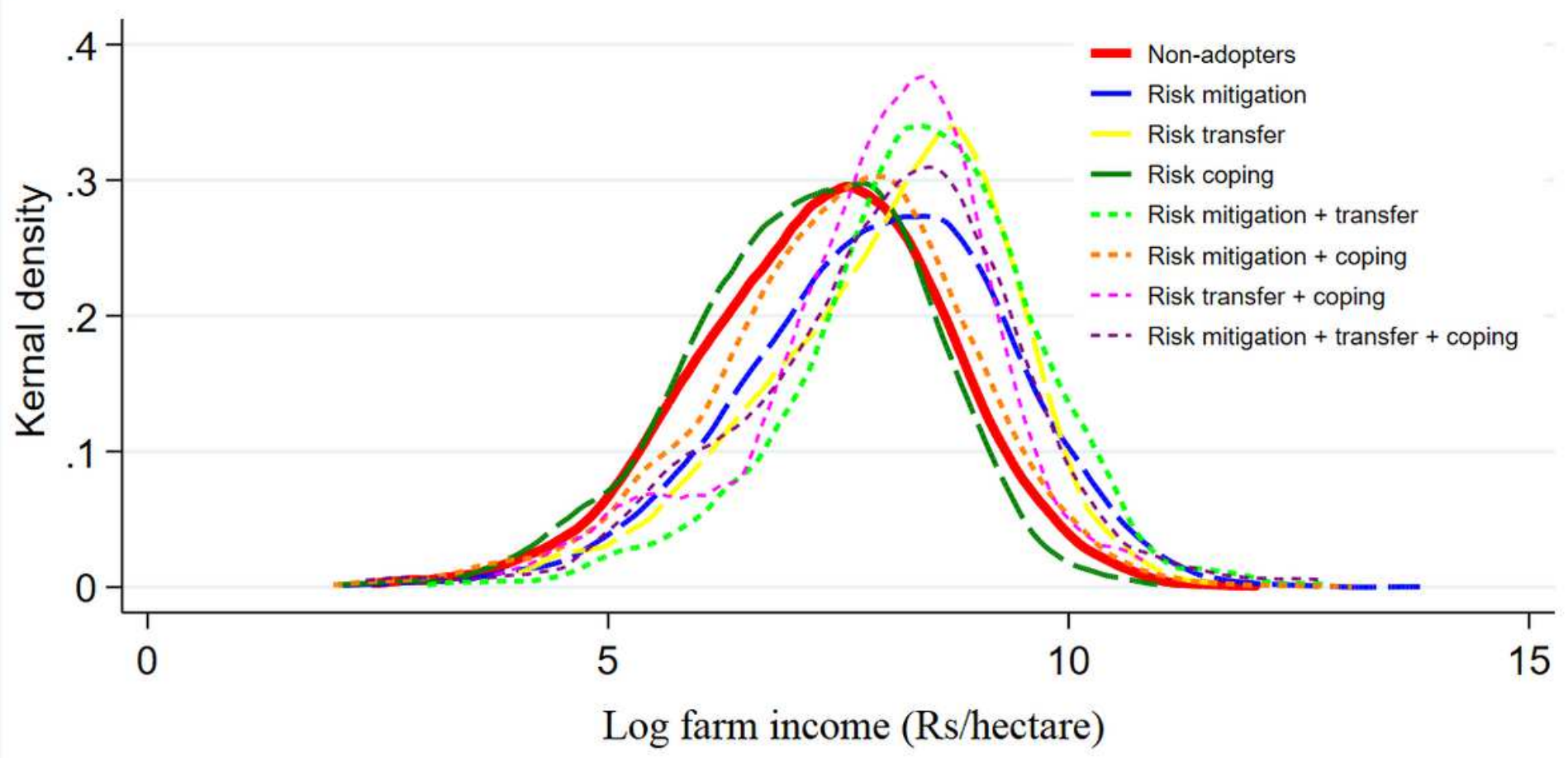

\section{Figure 1}

Unconditional kernel densities

\section{Supplementary Files}

This is a list of supplementary files associated with this preprint. Click to download.

- Tables.pdf

- Appendices.docx

- CCSupplemantaryTables.docx 